\title{
Compreender, agir e incluir sob a ótica de Paulo Freire - Transtorno de Déficit de Atenção e Hiperatividade (TDAH) e Transtorno Opositivo Desafiador (TOD), breve análise comparativa
}

\author{
Understand, act and include from the perspective of Paulo Freire - Attention Deficit Hyperactivity \\ Disorder (ADHD) and Oppositional Defiant Disorder (ODD), brief comparative analysis
}

Comprender, actuar e incluir desde la perspectiva de Paulo Freire - Trastorno por Déficit de

Atención e Hiperactividad (TDAH) y Trastorno de Oposición Desafiante (ODD), breve análisis comparativo

Recebido: 14/11/2021 | Revisado: 28/11/2021 | Aceito: 29/11/2021 | Publicado: 09/12/2021

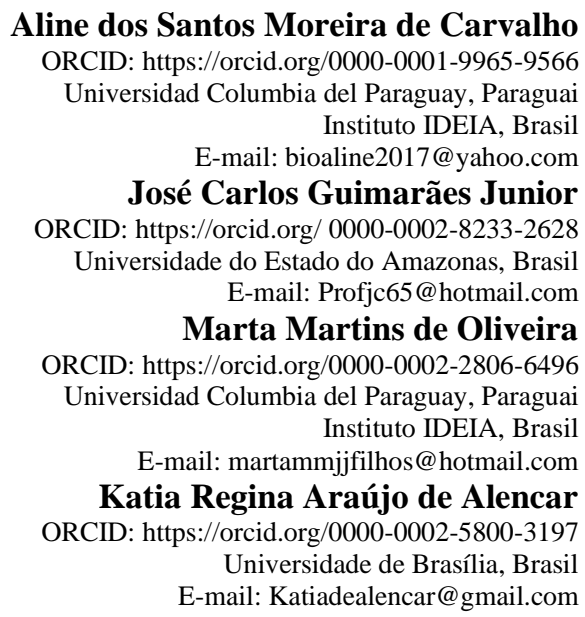

\begin{abstract}
Resumo
A pedagogia que Paulo Freire construiu ao longo do seu trabalho transformou a visão sobre a educação brasileira. $\mathrm{O}$ pedagogo desenvolveu uma pedagogia libertadora e problematizadora que é, ao mesmo tempo, inclusiva e compreende as diferenças e a heterogeneidade da educação, incluindo a população de educandos que têm o Transtorno de Déficit de Atenção e Hiperatividade assim como o Transtorno Opositor Desafiador. Objetivando analisar a pedagogia inclusiva de Freire, o TDAH e o TOD, a metodologia utilizada foi de pesquisa bibliográfica exploratória de caráter qualitativo. Foi feita uma análise textual buscando pontos em comum, comparativos e correlacionais entre as temáticas abordadas. Os principais resultados encontrados foram a constatação do caráter inclusivo da pedagogia de Freire, na abordagem dos transtornos, as relações entre o TDAH e o TOD. Tanto esses como as discussões foram apresentados juntos, em quatro títulos, e as conclusões apresentadas nas considerações finais.
\end{abstract}

Palavras-chave: Inclusão; Paulo Freire; Pedagogia; TDAH; TOD.

\begin{abstract}
The pedagogy that Paulo Freire built throughout his work transformed the view of Brazilian education. The educator has developed a liberating and problematizing pedagogy that is, at the same time, inclusive and understands the differences and heterogeneity of education, including the population of learners who have Attention Deficit Hyperactivity Disorder as well as Oppositional Defiant Disorder. Aiming to analyze the inclusive pedagogy of Freire, the ADHD and the TOD, the methodology used was exploratory bibliographical research with a qualitative character. A textual analysis was carried out seeking common, comparative and correlational points between the themes addressed. The main results found were the verification of the inclusive character of Freire's pedagogy, in the approach to disorders, the relationship between ADHD and ODD. Both these and the discussions were presented together, under four headings, and the conclusions presented in the closing remarks.
\end{abstract}

Keywords: Inclusion; Paulo Freire; Pedagogy; ADHD; TOD. 


\begin{abstract}
Resumen
La pedagogía que construyó Paulo Freire a lo largo de su obra transformó la visión de la educación brasileña. El educador ha desarrollado una pedagogía liberadora y problematizadora que es, al mismo tiempo, inclusiva y comprende las diferencias y heterogeneidad de la educación, incluyendo la población de educandos que padecen Trastorno por Déficit de Atención e Hiperactividad así como Trastorno Oposicional Desafiante. Con el objetivo de analizar la pedagogía inclusiva de Freire, el TDAH y el DOT, la metodología utilizada fue la investigación bibliográfica exploratoria de carácter cualitativo. Se realizó un análisis textual buscando puntos comunes, comparativos y correlacionales entre los temas abordados. Los principales resultados encontrados fueron la verificación del carácter inclusivo de la pedagogía de Freire, en el abordaje de los trastornos, la relación entre TDAH y TND. Tanto estos como los debates se presentaron juntos, bajo cuatro títulos, y las conclusiones se presentaron en las observaciones finales.
\end{abstract}

Palabras clave: Inclusión; Paulo Freire; Pedagogía; TDAH; TOD.

\title{
1. Introdução
}

Paulo Freire é considerado o patrono da educação brasileira pois suas ideias transformaram a pedagogia praticada no país. Seus ideais e pensamentos estão refletidos em suas obras que propõem uma educação transformadora, que liberta o oprimido dentro de um sistema opressor, transforma o sujeito e através desse, a realidade social, política e econômica, fazendo daquele um ser autônomo, incluso na sociedade e participante dessa.

A educação possui muitos desafios, dentre os quais estão os estudantes com transtornos que implicam em dificuldades de aprendizagem, como o Transtorno de Déficit de Atenção e Hiperatividade e o Transtorno Opositor Desafiador, que não são caracterizadores de necessidades educacionais especiais, correlacionam-se, e geram preocupação com a população portadora no contexto da educação inclusiva.

Dentro da afirmativa que a pedagogia de Freire não esconde seu caráter inclusivo e transformador, o estudo justificase pela necessidade de explorar a existência da relação entre a pedagogia inclusiva de Paulo Freire e os Transtornos TDAH e TOD e como essa se desenha na prática educativa. O mesmo tem como objetivo destacar o caráter inclusivo da pedagogia freireana, relacionando-a aos Transtornos de Déficit de Atenção e Opositor Desafiador, assim como caracterizar ambos e analisar a relação desenhada entre esses.

\section{Metodologia}

A metodologia utilizada foi de pesquisa bibliográfica, que segundo Marconi e Lakatos,

A pesquisa bibliográfica, ou de fontes secundárias, abrange toda bibliografia já tornada pública em relação ao tema de estudo, desde publicações avulsas, boletins, jornais, revistas, livros, pesquisas, monografias, teses, material cartográfico etc. [...] Dessa forma, a pesquisa bibliográfica não é mera repetição do que já foi dito ou escrito sobre certo assunto, mas propicia o exame de um tema sob novo enfoque ou abordagem, chegando a conclusões inovadoras (Lakatos, Marconi, 2010, p.166).

A pesquisa bibliográfica proposta é exploratória que, segundo Aaker, Kumar \& Day (2004), envolve geralmente abordagem qualitativa, uso de grupos de discussão, caracterizada pela ausência de hipóteses e para Mattar (2001), utiliza métodos versáteis compreendendo levantamentos em fontes secundárias, experiências, estudos de caso selecionados e também observação informal.

A pesquisa também possui caráter qualitativo que, segundo Trivinos (1987), trabalha os dados em busca de significados, baseando-se na percepção do fenômeno dentro do seu contexto, buscando captar a essência do fenômeno para explicar sua origem, relações e mudanças, assim como tentando intuir as consequências.

Nessa perspectiva foram elencados livros em material impresso assim como artigos científicos e periódicos em fontes virtuais confiáveis, anais de congressos, discussões e levantamentos que versam sobre a temática. 
Foi feita uma análise textual buscando pontos em comum, comparativos e correlações entre as temáticas abordadas. Os resultados e discussões floram apresentados em quatro títulos, e as conclusões apresentadas nas considerações finais.

\section{Desenvolvimento}

\section{A pedagogia de Paulo Freire}

A escola possui um papel social, ao qual lhe é confiada a promoção do sujeito, do homem como ser humano. Nesse sentido, faz-se necessária uma mudança de ideologia no pensar escola pela comunidade escolar, para que isso se reflita em suas ações (Schram; Carvalho, online).

O ser humano é um ser social capaz de ações objetivas que recriam a realidade para representa-la e muitas vezes, com relação ao concreto, demonstram conflitos pois seus discursos são submetidos a pressões de classes sociais, o que faz com que suas ideologias sejam determinadas pelas estruturas de classes sociais.

Sendo assim, no contexto de relações sociais acontecem as manifestações de opressão, discriminação e aceitação dos desviantes (do que se é considerado normal em determinada cultura ou sociedade), ou seja, a exclusão social é fundamentada em sentimentos e ideologias aprendidos culturalmente. Exclusão essa que Paulo Freire sempre se demostrou contrário e que continua perpetuando a condição de incapacidade atribuída aos "diferentes" pois acreditava que através da educação o ser humano torna-se autônomo e pode transformar a realidade política, crítica e democrática.

O sistema educacional hoje requer uma escola capaz de pôr em prática um currículo eficaz e de relevância que faça com que o processo de ensino-aprendizagem aconteça de fato, inclusiva, que possua uma proposta político pedagógica fundamentada em uma pedagogia crítica que fomente os educandos a pensarem de forma crítica a realidade social, histórica e política na qual estão inseridos, que possam conviver verdadeiramente respeitando as diferenças e sejam transformadores da realidade através da educação. Para o educador é requerido, de acordo com Paulo Freire, que seja aquele que "ensina os conteúdos de sua disciplina com rigor e com rigor cobra a produção dos educandos, mas não esconde a sua opção política na neutralidade impossível de seu que-fazer" (Freire, 2000, p. 44 apud Schram; Carvalho, online, s.p.).

Para Freire, o educador deve ser consciente de seu papel como formador de seres críticos e igualmente consciente do todo em torno, para gerar autonomia, mediante a educação libertadora. Nesse sentido, o educador tem papel fundamental no processo educativo e, para Paulo Freire,

Não se permite a dúvida em torno do direito, de um lado, que os meninos e as meninas do povo têm de saber a mesma matemática, a mesma física, a mesma biologia que os meninos e as meninas das "zonas felizes" da cidade aprendem mas, de outro, jamais aceita que o ensino de não importa qual conteúdo possa dar-se alheado da análise crítica de como funciona a sociedade. (ibidem).

E educação deseja uma escola que juntamente com os educadores apresente mudanças necessárias para a transformação social, fazendo da sociedade mais justa e igualitária, o que ocorrerá somente se a escola possuir clareza de seu real papel social exemplificada através de seu currículo, da sua proposta pedagógica, do sistema de avaliação, demonstrando compromisso, e capacidade de agir e refletir sobre a realidade, compreendendo as necessidades e promovendo a inclusão escolar e social (ibidem).

Paulo Freire, como educador, afirma que "se o meu compromisso é realmente com o homem concreto, com a causa de sua humanização, de sua libertação, não posso por isso mesmo prescindir da ciência, nem da tecnologia, com as quais me vou instrumentando para melhor lutar por esta causa" (Freire, 2007, p. 22 apud ibidem) e acrescenta que esse deve assumir o "compromisso com os destinos do país. Compromisso com seu povo. Com o homem concreto. Compromisso com o ser mais deste homem" (Freire, 2007, p. 25 apud ibidem). 
Com relação a educação inclusiva, no sentido de compreender a todos chamados "diferentes", a pedagogia de Paulo Freire tem sido abordada para que cada um reconheça-se seres sujeitos a transformação que podem conquistar seus espaços na sociedade. Em seu livro Pedagogia da Autonomia, declara:

Gosto de ser homem, de ser gente, porque sei que a minha passagem pelo mundo não é predeterminada, preestabelecida. Que o meu "destino" não é um dado mas algo que precisa ser feito e de cuja responsabilidade não posso me eximir. Gosto de ser gente porque a História em que me faço com os outros e de cuja feitura tomo parte é um tempo de possibilidades e não de determinismo. Daí que insista tanto na problematização do futuro e recuse sua inexorabilidade (Freire, 2007, p. 58).

Nessa perspectiva, a educação vem quebrando paradigmas, valorizando a heterogeneidade humana e a diversidade.

E Paulo Freire apresenta-se como educador que discutiu a relação entre homem e sociedade, abordando a educação brasileira para torna-la melhor através do compromisso e participação de todos, como educação libertadora capaz de colaborar para o sujeito tornar-se protagonista de seu desenvolvimento, acontecido sob a orientação de educadores capacitados, responsáveis e conscientes. Para ele, a educação é um ato de amor e coragem que se sustenta no diálogo e na discussão, constituindo um processo de compreensão, ação e inclusão.

Conceito esse que resulta numa educação para a liberdade e problematizadora, ou inclusiva que acontece horizontalmente, na qual educador e educando estabelecem diálogo constante, mostrando ao segundo que este não está sozinho no mundo e sim, acompanhado do mundo, no processo de transformação das realidades.

Para Freire (2007, p. 70), “A educação como prática da liberdade, ao contrário daquela que é prática da dominação, implica na negação do homem abstrato, isolado, solto, desligado do mundo, assim também na negação do mundo como uma realidade ausente dos homens".

Portanto, a compreensão acontece mediante o conhecimento, aceitação e diálogo, passando pela criticidade; após aquela, acontece a ação no sentido de transformação, de fazer acontecer, e como desdobramento, a inclusão, onde diferença e diversidade são anuladas diante da quebra de ideologias culturalmente enraizadas que não são verdadeiras.

Dentre algumas realidades encontradas em escolas brasileiras, alunos com TDAH e TOD apresentam problemas de aprendizagem, sendo necessário atenção especial por parte do educador e da escola que deve oferecer apoio pedagógico para que esses alunos tenham oportunidades iguais aos demais, mesmo que não exista legislação específica para esses casos, ou seja, não estão incluídos em casos de necessidades educacionais especiais, apesar de esse processo poder ser considerado, sob a ótica de Paulo Freire, inclusivo.

\section{Transtorno do Déficit de Atenção e Hiperatividade (TDAH)}

O TDAH passou a ser mais observado e, portanto, adquirindo relevante posição de tema recorrente nas discussões nos ambientes acadêmicos e familiares a partir dos anos 80 passando a ser considerado como o principal distúrbio psicológico em crianças, entretanto com baixa disseminação pelos atores envolvidos. Percebe-se na atualidade um crescente número de grupos de apoio que se articulam, interagem e atuam como disseminadores de informações sobre o transtorno promovendo significativa exposição na mídia. Como resultado, observa-se que mais crianças são diagnosticadas e tratadas corretamente (ITPAC, 2012).

O TDAH surgiu na literatura médica ainda no século XIX onde apareceram as primeiras referências a transtornos de comportamento, porém não era assim denominada. Os nomes variaram de acordo com o tempo, como a década de 1940, "lesão cerebral mínima”, em 1962 "disfunção cerebral mínima”, porém já era reconhecido que era apenas uma disfunção e não uma lesão. Hoje, os nomes variam entre transtorno por déficit de atenção com hiperatividade, tipo desatento, hiperativo, impulsivo e 
combinado, de acordo com o (DSM) - IV Manual de Diagnóstico e Estatística das Perturbações Mentais (Bromberg, 2002; Silva, 2004).

A maioria dos educadores tiveram contato com o mesmo, seja conhecendo, convivendo ou ensinando alguma criança ou adolescente portador desse transtorno. A maior dificuldade que familiares, pais e muitas vezes educadores enfrentam é a falta de conhecimento e/ou orientação sobre o transtorno.

Ao longo do tempo, tem se apresentado como um fenômeno incensado por diversas controvérsias, materialidades e narrativas que tem conquistado espaços nas produções acadêmico-científicas no decorrer dos últimos dois séculos. Neste período de crescente busca pelo conhecimento neste campo e principalmente pelos distúrbios comportamentais que se apresentavam também de forma crescente, se proliferaram as discussões sobre ciência enquanto produtora de um saber neutro e generalizado.

Os educadores por meio de seus discursos e práticas buscam a compreensão deste fenômeno e entre estes encontra-se Paulo Freire, a quem como supramencionado interessava a inclusão destes indivíduos não pela diferenciação comportamental, mas e antes pela liberdade e abrangência, que segundo este pesquisador ao se compreender este fenômeno estabelecer-se-ia um diálogo entre educando e educador de forma a se promover a aceitação para inclusão.

Destaca-se que em grande parte, a sintomatologia do TDAH pode ser observada desde a tenra infância, sendo mais perceptíveis no inicio da fase escolar do indivíduo, quando os professores conseguem identificar hiperatividade e dificuldades de manter a atenção, por meio de uma análise comparativa destes comportamentos em grupos, por exemplo de mesma faixa etária.

De acordo com o Ministério da Saúde cerca de 3 a 6\% da população mundial sofre com o Transtorno do Déficit de Atenção e Hiperatividade (Saúde, 2014).

Marco A. Arruda, em seu livro "Levados da Breca", sintetiza em uma única frase o que é o TDAH. Ele explica:

O TDAH é um transtorno mental crônico, multifatorial, neurobiológico, de alta frequência e grande impacto sobre o portador, sua família e a sociedade e caracterizado por dificuldade de atenção, hiperatividade e impulsividade que se combinam em graus variáveis e têm início na primeira infância, podendo persistir até a vida adulta (Arruda, 2006. p. 9).

Goldstein e Goldstein 1994 (apud Araújo, 2004) afirmam que hiperatividade é prevalente na infância. A criança apresenta-se com energia ilimitada (aparentemente) e sempre age com impulsividade, acreditam ser uma disfunção cerebral.

Hiperatividade é um transtorno comportamental, com excessivas mudanças de atitudes e atividades recorrentes, o sujeito não consegue realizar as atividades normais do dia-a-dia (Topczewski, 1999 apud ibidem).

Com relação as causas do TDAH, muitos autores discutem hipóteses, pois não existem certezas comprovadas. Os autores concordam que as prováveis causas estão relacionadas a problemas cerebrais (lesões e disfunções cerebrais), hereditariedade, traumas durante o parto, problemas familiares. A hereditariedade é um fator prevalente entre os autores pois o TDAH é prevalente no sexo masculino, há casos semelhantes entre parentes próximos e mães hiperativas (Cypel, 2000; Rohde; Benczik, 1999; Topcziwiski, 1999 apud Araújo, 2004).

Segundo o DSM-IV, a característica marcante do TDAH é o padrão repetitivo e insistente de falta de atenção e/ou impulsividade ou hiperatividade. (DSM-IV, 2003).

A hiperatividade é um conjunto de sinais e sintomas que apresentam desatenção, hiperatividade e impulsividade, que possui diagnóstico clínico (Cypel, 2000 apud Araújo, 2004); é um transtorno classificado de saúde mental e possui três características básicas: impulsividade, a desatenção e a hiperatividade, implicando em grande impacto na vida de crianças, adolescente e adultos que possuem o transtorno assim como na das pessoas que convivem com essas (Rohde \& Benezik, 2000 apud ibidem). 
Mencionando Caliman (2010), os três sintomas que caracterizam os tipos do transtorno se desdobram em quadros mais específicos, o que agrava e muito a condição dessas crianças e adolescentes (Caliman, 2010).

Por ser um transtorno no desenvolvimento e no autocontrole, a criança ou adolescente não consegue acomodar-se nem manter a concentração, apresenta desatenção, dificuldade em resistir às distrações, esquecimentos, desorganização mental, física e espacial, dificuldades com passagem de tempo o que causa atrasos e adiamentos, dificuldades em seguir orientações, problemas de memória em curto prazo, inquietação (mexer pés e mãos ao mesmo tempo, ficar batendo a perna o tempo todo), faz muitas coisas ao mesmo tempo, tendência a compulsão, intolerante, impaciente, instabilidade do humor, não consegue expressar-se corretamente, explosivo, hipersensível, instável sexualmente são crianças e adolescentes desafiantes tanto para pais como para os professores (Azeredo, 2015).

O TDAH apresenta três principais sintomas que, de acordo com a combinação ou predominância de um ou mais e suas manifestações clínicas, definem os subtipos de TDAH que o indivíduo possui e que são: o déficit de atenção ou desatenção que é o sintoma central do transtorno (mais comum em meninas); a hiperatividade que é o mais facilmente identificado e a impulsividade é o sintoma que geralmente os pais não reconhecem pois pode passar despercebido como uma pequena ansiedade (Arruda, 2006)

Os subtipos são: predomínio da desatenção - atinge de 20 a $30 \%$ dos casos; predomínio da Hiperatividade - atinge $15 \%$ dos casos; sintomas combinados -50 a $75 \%$ dos casos (ibidem).

\section{- O Déficit de Atenção}

O Déficit de atenção ou desatenção é o sintoma central do TDAH. "Ele é comentado por pais e professores das seguintes formas: "parece não ouvir", "parece que está no mundo da lua", "Não termina as tarefas"," costuma perder as coisas", dentre outros. De acordo com Douglas (1983) e Newcorn et al. (2001), estudos revelam que a maior dificuldade dos portadores não está em prestar atenção imediata e sim em manter o esforço de continuar prestando atenção por algum tempo ou a capacidade de manter atenção as tarefas ou a chamada "vigilância" (Douglas, 1983; Newcorn et al., 2001).

Um problema específico dentro desse sintoma e muito comum, é a distração, essa observação é pontuada muitas vezes por parte de pais e professores dessa população - as crianças distraem muito facilmente, por menor que seja o evento que esteja fora do conteúdo da tarefa. Porém estudos contrapões caracterizando como contraditórios alegando estar a dificuldade em manter a atenção, por isso a distração é muito comum (Arruda, 2006).

De acordo com a observação pontuada por pais e professores, as crianças com esse subtipo apresentam tempo cognitivo lento, ou seja, são avaliadas como lentas, passivas, preguiçosas, sonhadoras, pasmadas, confusas, mesmo que esses sintomas pareçam paradoxais com relação ao transtorno (Barkley, 2008).

\section{- Hiperatividade}

Esse é o sintoma mais facilmente identificado em crianças com TDAH. O quadro observado é da criança agitada, que não consegue ficar muito tempo parada, que fala muito, não espera os pais ou professores terminarem de falar e já estão fazendo as tarefas muitas das vezes errando por não conseguirem esperar, que fica batendo o pé no chão o tempo todo - é uma inquietação corporal (Arruda, 2006).

De acordo com Barkley (2008), nesse sintoma são observadas atividades excessivas ou inadequadas ao desenvolvimento da idade, sendo motora ou vocal (a criança não para de se mexer e não para de falar), inquietação, agitação e brutalidade em movimentar-se. Essas crianças são descritas como "a todo vapor", "tagarela", "a mil por hora", "está sempre murmurando, fazendo sons estranhos", "sempre se contorcendo" (Barkley, 2008). 


\section{- Impulsividade}

Segundo Barkley (2008) essa forma de impulsividade característica do transtorno envolve descontrole comportamental, inibição prolongada fraca, incapacidade de demorar a responder, ou incapazes de guardar as respostas, ou seja, de não falar. É importante observar que esse sintoma implica diretamente no déficit de atenção, pois pela incapacidade de ficar quieto, o aluno não consegue manter o tempo e esforço necessário para a atenção (Barkley,2008).

Dessa forma, pode prejudicar o relacionamento social das crianças e adolescentes, uma vez que a impulsividade não permite que esperem o outro terminar de falar, interrompendo o outro, provocando discussões; impedem que saibam esperar, entre outros desdobramentos.

O TDAH por ser um transtorno neurobiológico que apresenta sintomas desmistifica a afirmativa de que esses indivíduos são mau caráter ou mal-educados, apenas possuem um transtorno comportamental que precisa ser tratado.

\section{Transtorno Opositor Desafiador (TOD)}

Observa-se no cotidiano dos ambientes escolares e acadêmicos que há pouca informação sobre este transtorno e suas especificidades o que pode causar diversos entendimentos tais como: ausência de limites, desobediência e até mesmo hiperatividade. Sendo o ser humano considerando como um ser de relações sociais segundo Strey, pág. 59, 2002). Neste estudo admite-se que o indivíduo assume e incorpora como sendo suas as regras normas, crenças e valores dos grupos onde participa, quais sejam: a família, amigos (seus pares) talvez sem essa percepção identificada.

Nas relações de convivência os indivíduos influenciam e são influenciados na maneira de se conviver, de se fazer, de se criar, construir, de se elaborar e nas expressões de afetividade (Savoya, 1989).

Tantas são as oportunidades para professores e educadores que se depararam com alunos que demonstram comportamentos difíceis de se lidar, pois por vezes estes indivíduos interagem de maneira grosseira com seus professores, evidenciando por interpretação primeira, uma ausência de limites, educação respeito e agem com violência e agressividade resultando no comprometimento de seu processo de aprendizagem.

Segundo APA (2014):

Quando o transtorno de oposição desafiante é persistente ao longo do desenvolvimento, os indivíduos com o transtorno vivenciam conflitos frequentes com pais, professores, supervisores, pares e parceiros românticos. Com frequência, tais problemas resultam em prejuízos significativos no ajustamento emocional, social, acadêmico e profissional do indivíduo. (APA, 2014, p. 465).

Verifica-se ao longo do tempo das observações deste fenômeno, que podem existir possíveis causas e fatores que contribuem para estes comportamentos, reforçando a necessidade de ampliação de pesquisas sobre o TOD visando seu aprofundamento, proporcionando melhores respostas para o entendimento e compreensão dos professores diante dessas situações.

Abnerson et al. (1999 apud Serra-Pinheiro et al., 2004) caracteriza o Transtorno Opositor Desafiador como um transtorno disruptivo que compreende um padrão global de desobediência, desafio e um comportamento hostil.

O TOD é uma condição que afeta a criança de forma comportamental pois essa é acometida por uma sensação de irritabilidade constante, com acessos de raiva e indisciplina. O TOD é considerado como uma comorbidade do TDAH (Neurosaber, 2017).

Crianças com TOD apresentam maior disfunção familiar que controles psiquiátricos (Greene et al., 2002 apud SerraPinheiro; Guimarães; Serrano, 2005), utilizam abordagens negativas diante de conflitos (Edwards et al., 2001 apud SerraPinheiro; Guimarães; Serrano, 2005), têm taxas de transtornos internalizantes bastante altas (Carlson et al., 1997 apud Serra- 
Pinheiro; Guimarães; Serrano, 2005), são rejeitados pelos colegas e têm taxas de recusa escolar altas (Harada et al., 2002 apud Serra-Pinheiro et al., 2005).

O TOD está associado a um mau prognóstico para a vida adulta, expresso por alto índice de depressão e tentativas de suicídio assim como o abuso de substâncias e comprometimentos legais (Capaldi, 1992; Tremblay et al., 1994 apud ibidem). E possui alta taxa de associação com o TDAH (ibidem).

O ambiente doméstico dessas crianças e adolescentes habitualmente é bastante complexo e conturbado, marcado por divergências e conflitos e existem fatores genéticos e neurofisiológicos que predispões o desenvolvimento do TOD (Neurosaber, 2017).

O Manual Diagnóstico e Estatístico de Transtornos Mentais (DSM-V) lista critérios emocionais e comportamentais com duração média de seis meses, que são: humor zangado e irritável (perda de paciência com frequência e rapidamente, sensível e facilmente incomodado pelos demais e muitas vezes sente raiva e ressentimento) e comportamento argumentativo e desafiador (rancor e vingança, pelo menos duas vezes em seis meses).

Serra-Pinheiro et al. (2004) apresentam, em seus estudos, algumas correlações importantes a respeito do TOD, assim distribuídas: correlatos neurobiológicos - indivíduos com TOD possuem níveis de andrógenos adrenais mais altos que os que não têm o transtorno e apresentam frequência cardíaca mais baixa (Van Goozen et al., 2000 apud Serra-Pinheiro et al., 2004); genéticos - Nadder et al. (2002 apud Serra-Pinheiro et al., 2004) sugeriram, com base em um estudo com gêmeos, que havia um risco genético para a concorrência de TOD com TDAH e também para a persistência dos sintomas de TOD; cognitivos Coy et al. (2001) concluíram que as crianças com TOD geraram soluções agressivas aos problemas comparadas a controles e Van Goozen et al. (2004), ao testarem o funcionamento executivo em crianças com TDO com e sem TDAH e controles normais afirmam que os indivíduos com TOD (ambos os grupos) apresentaram desenvolvimento abaixo dos demais grupos (Serra-Pinheiro et al., 2004).

Quanto a aspectos familiares, autores concordam que existe prevalência de relações disfuncionais entre os pais de crianças e adolescentes com TOD, assim como pais divorciados e em baixa situação socioeconômica, e um ambiente domiciliar conturbado (ibidem).

Em relação ao tratamento, não existe tratamento farmacológico estabelecido, é considerado positivo o uso de antipsicóticos ativos (Campbell et al., 1984 Serra-Pinheiro; Guimarães; Serrano, 2005) e atípicos (Ad Dab’Bagh et al., 2000 apud Serra-Pinheiro et al., 2005), anticonvulsivantes (Dinivan et al., 1997 apud Serra-Pinheiro; Guimarães; Serrano, 2005) e remédios para agressão ou mesmo sintomas de TOD (Hunt et al., 1986 apud Serra-Pinheiro et al., 2005).

A terapia cognitivo comportamental é uma terapia não medicamentosa, que objetiva a mudança no tratamento de pais em relação aos filhos com TOD tem apresentado resultados positivos (Serra-Pinheiro et al., 2004).

Portanto o TOD é um transtorno que interfere diretamente nos indivíduos acometidos assim como na vida dos que com eles convivem.

\section{Das relações entre os transtornos}

A íntima correlação estabelecida entre ambos os transtornos é de comorbidade: o TOD é uma comorbidade do TDAH em 50\% dos casos. A prevalência de primeiro no segundo é de cerca de 50\%, muito mais alta do que na população geral. (Souza et al., 2001 apud ibidem). Kadesjo et al. (ibidem) comparando crianças com TDAH com e sem TOD, encontraram que o subtipo combinado é de maior gravidade de mais comuns em grupos comórbidos.

Um transtorno influencia em como o outro vai se manifestar, dentre essas, podem ser encontradas algumas características como: raiva, agressividade, desobediência, hostilidade, intolerância frustrações, desrespeito com solicitações, dentre outros. 
Cabe ressaltar que $1 / 3$ da população com TDAH apresenta o TOD, o que torna o transtorno mais complexo ainda (Neurosaber, 2017).

Entre as correlações encontradas: Gadow et al. (2002) compararam pacientes com TDO a pacientes com TDAH, a um grupo com essa comorbidade e a controles. Encontraram que pré-escolares com os dois transtornos tinham os mais altos escores de dificuldades com colegas e déficits de desenvolvimento; Carlson et al. (1997) demonstraram que crianças com ambos os transtornos tiveram um desempenho pior em termos de funcionamento social do que crianças somente com um dos transtornos e do que controles sem esses transtornos; crianças com TDO demonstraram menor dificuldade com aprendizado do que crianças com TDAH; Harada et al. (2002) encontraram que crianças que apresentavam somente TDO tiveram maior recusa à escola do que as que tinham TDAH e mesmo do que o grupo comórbido; Greene et al. (2002) também encontraram que TDO estava relacionado com disfunção social em comparação aos controles psiquiátricos (Serra-Pinheiro et al., 2004, p. 274).

\section{Considerações Finais}

Paulo Freire revolucionou o olhar da pedagogia sobre a educação brasileira, enfrentando ideologias enraizadas culturalmente e quebrando paradigmas. A educação para a liberdade é uma máxima a ser alcançada por todos os envolvidos no processo educativo ou, em suma, por todos os que acreditam no poder da educação transformadora, libertadora e inclusiva.

Deve-se observar, diante do discurso da inclusão escolar, que essa deve, por sua natureza, compreender a população de educandos que possuem dificuldades de aprendizagem, mas que não estão compreendidos em casos de necessidade educacional especial, como os educandos com os Transtornos de Déficit de Atenção e Opositor Desafiador.

Diante dos aspectos abordados e analisados, destaca-se a íntima relação que um transtorno possui com o outro, alcançando 50\% de casos de comorbidade, sendo o Opositor Desafiador assim caracterizado; os portadores apresentam piores aspectos comportamentais e de socialização em casos combinados e maior dificuldade de aprendizagem.

Devido não serem caracterizadores de necessidades especiais, a população portadora está matriculada em classes regulares, o que faz com que os educadores necessitem estar capacitados para desenvolver a aprendizagem e principalmente a inclusão desses alunos. Nesse aspecto, a abordagem freireana é de grande auxílio pois visa a autonomia, respeitando as individualidades, porém desenvolvendo-se no relacionamento consigo e com os outros.

Nessa perspectiva, destaca-se o saber ser, para desenvolver o compreender, o agir e o incluir, com amor e assim, educar para a liberdade transformadora.

\section{Referências}

Aaker, D. et al, (2004). Pesquisa de marketing. Atlas.

Amorim, C. (2017). O TDAH tem cura? Website Déficit de Atenção. https://dda deficitdeatencao.com.br/ artigos/tdah-tem-cura.html.

APA, Apsychiatric Association. (2014) Manual Diagnóstico de transtornos mentais (DSM - 5). https://periodicos.pucpr.br/psicologiaargumento/article/view/25743.

Arruda, M. A. (2006) Levados da Breca - um guia sobre crianças e adolescentes com Transtorno do Déficit de Atenção e Hiperatividade (TDAH). Ribeirão Preto. Website Estante virtual. https://www.estantevirtual.com.br/livros/marco-a-arruda/levados-da-breca/2178283709.

Azeredo, R. M. D. de. (2015) O TDAH na perspectiva da inclusão. Website AVM educacional.

Barkley, R. A. (2020). Transtorno de déficit de atenção/hiperatividade - Manual para diagnóstico e tratamento. Pdf. https://grupoautentica.com.br/autentica/livros/tdah-transtorno-do-deficit-de-atencao-com-hiperatividade/1831.

Braga, C. (2017). Entendendo o TDAH em 10 passos - orientações aos pais e professores. E-book.

Caliman, L. V. (2010) Notas sobre a história oficial do transtorno do déficit de atenção/hiperatividade-TDAH Website Scielo. http://pepsic.bvsalud.org/scielo.php?script=sci_arttext\&pid=S1414-98932010000100005. 
Research, Society and Development, v. 10, n. 16, e158101623305, 2021

(CC BY 4.0) | ISSN 2525-3409 | DOI: http://dx.doi.org/10.33448/rsd-v10i16.23305

Carvalho, et. al., J. A. (2012). TDAH: Considerações sobre o transtorno do déficit de atenção e hiperatividade. Revista Científica do ITPAC, Araguaína, 5(3), https://assets.unitpac.com.br/arquivos/Revista/53/5.pdf.

Cavalcante, D. (2021). TDAH e os desafios da leitura e escrita - relato de caso. Website Aprenderedivertido, https://docero.com.br/doc/sexx05c.

Freire, A. C. C.; \& Pondé, M. P. (2005). Estudo piloto da prevalência de TDAH entre crianças escolares na cidade de Salvador, Bahia, Brasil. Arquivos de Neuropsiquiatria, 63(2), 474-478.

Freire, P. (2007). Pedagogia da Autonomia: saberes necessários à prática educativa. (35a ed.), Paz e Terra (Coleção Leitura).

Gil, A. C. (2008). Como elaborar projetos de pesquisa. (5a ed.), Atlas.

Jou et al., G. I. (2010). Transtorno de Déficit de Atenção e Hiperatividade: Um Olhar no Ensino Fundamental. Website Scielo. https://www.scielo.br/j/prc/a/Q4GXdJzTPvBdgwjwNZv8mrw/?lang=pt\&format=pdf

Maia, M. I. R.; \& Confortin, H. (2015). TDAH e aprendizagem: um desafio para a educação.

Marques, L. P.; Romualdo, A. dos S. (online). Paulo Freire e a educação inclusiva. Eixo 1 - A educação que emancipa frente às injustiças, desigualdades e vulnerabilidades. http://www.acervo.paulofreire.org:8080/jspui/bitstream/7891/3512/1/FPF_PTPF_01_0435.

Mattar, F. N (2001). Pesquisa de marketing. (3a ed.), Atlas.

Neurosaber, Instituto. (2017). Transtorno opositivo desafiador no TDAH.

Pereira, R. A. (2010). A criança com TDAH e a escola. Website ABDA, https://tdah.org.br/a-crianca-com-tdah-e-a-escola/.

Savoia, M. G. (1989). Psicologia social. McGraw-Hill.

Schram, S. C.; \& Carvalho, M. A. B. (online). O pensar educação em Paulo Freire - para uma pedagogia de mudanças. 1-21, http://www.diaadiaeducacao.pr.gov.br/portals/pde/arquivos/852-2.pdf.

Serra-Pinheiro et al., (2004). Transtorno desafiador de oposição: uma revisão de correlatos neurobiológicos e ambientais, comorbidades, tratamento e prognóstico. Revista Brasileira de Psiquiatria, 26(4), 273-6, Scielo. https://www.scielo.br/j/rbp/a/7S44b NFFLpKBzTzVzXkSJDG/?format=pdf\&lang=pt>.

Serra-Pinheiro et al., (2005). Revista de Psiquiatria Clínica, $32 \quad$ (2), 68-72, https://www.scielo.br/j/rpc/a/YWG KDSh7XPCzyPSkDTLZkkz/?lang=en\&format=pdf.

Souza, L. de F. (2015). Práticas pedagógicas e metodologia de Paulo Freire. Pdf. Faculdade Calafiori. São Sebastião do Paraíso.

Strey, M. N. (2002). Psicologia Social Contemporânea. (7a ed.), Vozes.

Trivinos, A. (1987). Introdução à pesquisa em ciências sociais. Atlas. 